\title{
Risk Factors for Urinary Incontinence after Obstetric Vesicovaginal Fistula Closure in Guinea
}

\author{
Fatoumata Binta Balde ${ }^{*}$, Abdoulaye Bobo Diallo², Abdoulaye Toure ${ }^{3}$, Daouda Kante², \\ Thierno Mamadou Oury Diallo², Alhafiz Lamadine ${ }^{1}$, Diao Cisse ${ }^{2}$, Olivier Kouadio ${ }^{3}$ \\ ${ }^{1}$ Faculty of Medical and Paramedical Sciences, Kofi Annan University of Guinea, Conakry, Guinea \\ ${ }^{2}$ Department of Urology, CHU Ignaace Deen of Conakry, Conakry, Guinea \\ ${ }^{3}$ Chair of Public Health and Pharmaceutical Legislation, Gamal Abdel Nasser University of Guinea, Conakry, Guinea \\ Email: *Fatoumatabinta.balde@usmba.ac.ma
}

How to cite this paper: Balde, F.B., Diallo, A.B., Toure, A., Kante, D., Diallo, T.M.O., Lamadine, A., Cisse, D. and Kouadio, O. (2021) Risk Factors for Urinary Incontinence after Obstetric Vesicovaginal Fistula Closure in Guinea. Surgical Science, 12, 1-8. https://doi.org/10.4236/ss.2021.121001

Received: December 20, 2020

Accepted: January 26, 2021

Published: January 29, 2021

Copyright $\odot 2021$ by author(s) and Scientific Research Publishing Inc. This work is licensed under the Creative Commons Attribution International License (CC BY 4.0).

http://creativecommons.org/licenses/by/4.0/

\begin{abstract}
Introduction: Urinary incontinence after closure of vesicovaginal fistula is any involuntary loss of urine that a patient complains of. We aim to study the risk factors for urinary incontinence after closure of obstetric vesicovaginal fistula in Guinea in order to develop preventive measures to reduce its incidence. Materials and Methods: This was a retrospective, multiple center cohort of women operated on for obstetric vesicovaginal fistula during a 10-year period. Results: In 1770 vesicovaginal fistulas operated, 1347 were closed. 180 women $(13.36 \%)$ developed urinary incontinence. After multivariate analysis, the risk factors of urinary incontinence after closure of vesicovaginal fistula were: the patient's age, the anatomical type III, iterative surgical intervention, the brevity of the urethra and decrease in bladder capacity. Conclusion: Urinary incontinence after closure of vesicovaginal fistula is a frequent problem in Guinea, the prevention of which should be integrated into the management of fistulas.
\end{abstract}

\section{Keywords}

Vesicovaginal Fistula, Surgery, Urinary Incontinence

\section{Introduction}

Vesicovaginal fistula (VVF) is an abnormal communication between the bladder and/or its cervix and the vagina resulting in involuntary and permanent loss of urine [1]. Although the success rate of treatment is up to $92 \%$ in simple cases, there are few centers for the management of fistulas. On this relatively high rate 
of anatomic closure, a significant proportion of women remain with urinary incontinence (UI) [2].

It is clear that UI affects many spheres of life for affected women, including their physical and mental well-being, sexuality, social relationships, as well as their private and professional lives [3]. If it is possible at the cost of a real surgical effort to restore a satisfactory anatomy, the surgeon should not be satisfied with this. He must render continence otherwise, the result for patients remains exactly the same [4].

The study aims to determine the risk factors for urinary incontinence after closure of obstetric vesicovaginal fistula.

\section{Material and Methods}

The study covers all the obstetric fistula care centers in Guinea. The urology department of the Ignace Deen University and Hospital Center (Conakry). The maternity of the Jean Paul II Medico-social center (Conakry). The Djigui hope: social care center (Conakry). The maternity ward of the first degree hospital in (Kissidougou). The maternity ward of the Regional Hospital (Labé).

It was a retrospective, cohort of women operated for obstetric fistula during a 10-year period between January 1, 2005 and January 1, 2015.

The study focused on women operated for obstetric VVF during our study period and who met our selection criteria. We excluded the other forms of obstetric VVF (vesico-genito-rectal fistula and women in pregnancy). We carried out an exhaustive recruitment. We identified women in the consultation registers, individual medical records, operating report registers. We analyze patient's demographic data, medical record, surgical report and the short term follow-up.

The different characteristics of the women were presented in the form of mean \pm Standard deviation for the quantitative, frequency variables with a $95 \%$ confidence interval. The univariate analysis concerned the dependent variable or variable of interest (UI) and the following independent variables: the age of the patients, the obstetric history (parity, pregnancy on non closed VVF), fistula clinics characteristics (age of the fistula, anatomical type, condition of the bladder neck, condition of the urethra), management characteristics of the fistula (number of curative surgeries, surgical intervention and duration of urinary catheter) and post-operative features (shortness of the urethra and decrease in bladder capacity).

To compare the 2 groups of women, the Student's t-test was used when the Pearson's Chi-squared test was not applicable. During the multivariate analysis, the odds ratio (OR) was calculated to measure the effects of variables whose $\mathrm{P}$-value is $\geq 20 \%$ during the univariate analysis on the occurrence of urinary incontinence after treatment of obstetric VVF. Statistical significance was made when the P-value is less than 0.05 . Our data was processed by Epi-info software version 7.1.3 and then exported to Statistical Package for Social Scientists version 21 for analysis. 
Ethical considerations: the research protocol was submitted to the administration of the respective sites for validation before the start of data collection. Confidentiality was guaranteed.

\section{Results}

Of the 1347 closed VVF, 1167 women (86.64\%) had a bladder continence and 180 women $(13.36 \%)$ [8.46; 18.26] had UI. The proportion of UI in relation to all 1770 VVF treated was $10.17 \%[8.76 ; 11.57]$.

Average age 36.74 years [35.74; 39.72]; from 15 to 70 years old. 103 (57.22\%) [49.65; 64.55] had an age between 15 to 18 years at the time of the first parity and $7.78 \%[4.32 ; 12.71]$ under 15 years old. They were married in $60.56 \%$ housewives $85.38 \%$ and lived in rural areas $88.33 \%$. Women with UI had a higher first parity rate compared to those without UI. The mean age of VVF was $12.67( \pm 1.72)$ with extremes of 0.03 and 50 years. The clinical features were marked by destruction of the bladder neck and urethra with a predominance of type 3 in the group of women with UI (Table 1).

Among these 180 incontinent women, vaginal approach was the most used surgical approach in 174 women (97.89\%). The mean duration of the urinary catheter was $18.36( \pm 11.85)$ from 7 to 21 days. Postoperative features were marked by the shortness of the urethra in 107 cases or $59.44 \%$ and the decrease in bladder capacity in 73 cases or $40.55 \%$. Stress UI was the most common type in $43.33 \% .7 \%$ had urinary urgency UI, and $4 \%$ had mixed UI. However in 81 women (45\%), the type of UI was not determined. The surgical procedures consisted in addition to fistulorraphy, urethroplasty, making of a new cervix.

Table 1. Comparison of the clinical characteristics of vesicovaginal fistulas in the 2 groups of women in Guinea from January 1, 2005 to January 1, 2015.

\begin{tabular}{lccc}
\hline \multicolumn{1}{c}{ Clinics characteristics } & $\mathrm{IU}-\mathrm{n}=720(\%)$ & $\mathrm{IU}+\mathrm{n}=180(\%)$ & P-value \\
\hline Mean age (years) & 8.32 & 12.67 & 0.0000 \\
Bladder neck statut & & & 0.000 \\
Normal & $524(72.8)$ & $57(31.7)$ & \\
Partial destruction & $142(19.7)$ & $84(46.7)$ & \\
Total destruction & $51(7.1)$ & $38(21.1)$ & 0.000 \\
Urethra statut & & & \\
Normal & $545(75.7)$ & $2(1.1)$ & \\
Partial destruction & $136(18.9 \%)$ & $65(36.1)$ & \\
Total destruction & $8(1.1)$ & $81(45)$ & \\
Type of fistula & & & \\
Type 1 & $312(43.3)$ & $14(7.8)$ & \\
Type 2 & $271(37.6)$ & $74(41.1)$ & \\
Type 3 & $131(18.2)$ & $89(49.4)$ & \\
\hline
\end{tabular}

*Type: type 1: (rétro trigonal, trigonal), type 2 (bladder neck, urétral, urétral cervix without transversal section) et type 3 (cervix, urétral, urétral cervix with transversal section). 
Table 2. Multivariate analysis of risk factors for urinary incontinence after obstetric vesicovaginal fistula treatment in Guinea from January 1, 2005, to January 1, 2015.

\begin{tabular}{|c|c|c|c|}
\hline Variables & OR & IC $95 \%$ & P-Value \\
\hline Mean age of the patient & 1.2 & & 0.003 \\
\hline Mean age of the fistula & 1.07 & $1.01-1.06$ & 0.002 \\
\hline Parité & & & 0.367 \\
\hline First parity & 1.31 & $0.69-1.42$ & 0.4055 \\
\hline Low parity & 1.55 & $0.80-2.03$ & 0.1902 \\
\hline Involvement of de bladder neck & & & 0.096 \\
\hline Partial & 1.41 & $0.77-2.52$ & 0.254 \\
\hline Total & 2.45 & $1.08-5.53$ & 0.031 \\
\hline Type of the fistula & & & 0.002 \\
\hline Type 2 & 2.20 & $1.04-4.65$ & 0.038 \\
\hline Type 3 & 4.27 & $1.86-9.81$ & 0.001 \\
\hline Iterative surgical procedure & & & 0.000 \\
\hline First & 0.15 & $0.05-0.48$ & 0.000 \\
\hline third & 0.43 & $0.15-1.22$ & 0.144 \\
\hline Fourth or more & 0.56 & $0.18-1.76$ & 0.328 \\
\hline Duration of urinary catheter (days) & & & 0.279 \\
\hline $8-14$ & & 0 & 0.996 \\
\hline 15 and more & 0.4 & 0 & 0.996 \\
\hline Meatus plasty & 0.9 & 0 & 0.999 \\
\hline Shortness of the urethra & 5.32 & $2.73-10.37$ & 0.000 \\
\hline Reduction of bladder capacity & 1.76 & $1.04-2.98$ & 0.035 \\
\hline
\end{tabular}

Table 3. Comparison of the number of obstetric VVF documented in Guinea to wich in other countries.

\begin{tabular}{cccc}
\hline Auteurs & Country & Duration (year) & Number of VVF \\
\hline Our study & Guinea & 10 & 1770 \\
S. M. Gueye [5] & Senegal & 6 & 123 \\
Benchekroun [6] & Morocco & 30 & 1050 \\
R. Kimassoum [7] & Chad & 3 & 363 \\
Bernis L [8] & Developing countries & - & -
\end{tabular}

Women with UI had the most multiple procedures to get the fistula closed. The risk factors are represented in Table 2.

\section{Discussion}

VVF is a public health problem whose circumstances of occurrence and incidence vary according to the level of health development from one country to another [5]. One of the most visible indicators of the huge differences in health between developed and developing countries is the persistent incidence of ob- 
stetric fistula in resource-poor regions [6]. We compare the number of documented fistulas compared to other countries [5] [6] [7] [8] (Table 3).

The frequency of UI after closure of obstetric VVF was 13.36\% 95\% [8.46; 18.26]. This result, although less than $17.5 \%$ [14.8 to 20.2] found by A. Delamou [9] in Guinea, the difference is not statistically significant. A. Lewis [8] in Sierra Leone reports a $10 \%$ prevalence of UI after FVV repair. The average age of incontinent women was $36.74 \%$. R. Kimassoum [7] in Chad found an average age of 26.8 years. In the series of A. Browning [10] in Ethiopia, the women were younger 22.5 years. One hundred and three (103) women were between 15 and 18 years of age at the time of the first parity. Analysis of the obstetric history shows that $26.11 \%$ of incontinent women continued to conceive even though their fistulas were not closed. The time of surgery is much discussed, but in most cases, a 3-month deadline is respected. Early management could expose to inflammatory tissue and tissue bleeding easily [2]. Women lived with their fistula from 0.03 to 50 years. In Ethiopia, A. Browning [10] found fistulas between 0.16 and 50 years old.

The fistulas which interest the continence system were more frequent affecting the bladder neck with urethral destruction. These results are consistent with data from the literature which states that UI is more common in fistulas involving the bladder neck (type 2), the urethra (type 2) but especially in transversal section (type 3) where the sphincter system may have completely disappeared [6] [7] [9] [11].

Of these incontinent women, $68.89 \%$ had iterative surgery to repair their fistula. This high rate of iterative surgery is well above $33 \%$ reported by Mr. Oxana [12] in Liberia; and that found by K. Waaldjik [13] in Nigeria 26\%. A. Demisew et al. [14] in Ethiopia reported a lower proportion (8.3\%) of women who underwent iterative surgery to repair their fistulas. This may have depended on the initial characteristics of the fistulas, associated lesions, surgical technique, postoperative care and the experience of the surgeon.

The first principles for the treatment of VVF were published in the XVIIth century by Hendrick Von Roonhuyse and since then, a significant number of techniques have been described [15]. For type 1 fistulas, simple fistulography was the procedure performed. In the other anatomical types, other surgical techniques were associated with fistulography such as the making of a new bladder neck, plasty of the urethral meatus, urethroplasty, cervix-urethral anastomosis.

The duration of urinary catheter is the subject of controversy, which will no doubt be resolved following ongoing randomized clinical studies [2]. The decision on the duration of the catheter is generally dependent on the complexity of the fistula. In our study, the duration of urinary catheter was from 7 and 21 days. M. A. Barone et al. [15] found that statistically 7 days of urinary catheter after repair of a VVF was not less than 14 days. This 7 -day duration should be used for the care of women after repair of a simple fistula. However, they did not find an association between the duration of bladder catheter and the risk of failure of the fistula closure, retention of urine, or residual UI. 
A. Delamou [9] in his study on the factors associated with the failure to close obstetric fistulas, found that the patient's age, the status of the urethra, the previous surgical repair were significantly associated with the occurrence of UI. The risk factors identified by A. Browning [10] in his study on the risk factors for residual UI after a VVF treatment were: parity, patient's age, destruction of the urethra and iterative surgery.

In our study, the risk factors for UI after treatment for VVF were: the age of the patient $(P=0.003)$; the age of the fistula $(P=0.002)$; anatomical type $2(P=$ $0.03) 1$; anatomical type $3(\mathrm{P}=0.001)$; total destruction of the bladder neck $(\mathrm{P}=$ $0.031)$; iterative surgery $(P=0.000)$; shortness of the urethra $(P=0.000)$ and decreased bladder capacity $(\mathrm{P}=0.035)$.

Women who had total destruction of the bladder neck were 2.45 times more likely to develop UI after their VVF were closed than women who had an intact bladder neck. The anatomical type 3 and the shortness of the urethra increased the chances of becoming incontinent by 4.27 and 5.32 times, respectively. However, unlike A. Browning [10] we found that parity (primiparity and paucity), increases the chances of becoming incontinent but alone does not constitute a risk factor for urinary incontinence after closure of VVF.

\section{Conclusions}

Urinary incontinence after closure of vesicovaginal fistula is a public health problem and remains a major challenge in obstetric vesicovaginal fistula surgery.

Its prevention must be integrated into the first management of obstetric fistula.

\section{Authors Contribution}

This work is a medical doctorate thesis carried out by FB BALDE. Under the direction of Prof. AB DIALLO, it is a national study carried out in collaboration with urologists and epidemiologists. All the authors actively participated from the conception to the elaboration of the final document.

\section{Acknowledgements}

Our thanks go to the heads of the various obstetric fistula care centres in Guinea. To Dr. Ludovic Falandry. To all those professionals who fight for the prevention and management of obstetric fistulas.

\section{Conflicts of Interest}

The authors declare no conflicts of interest regarding the publication of this paper.

\section{References}

[1] Hounasso, P.P., Rochat, C.H., Kulier, R. (2008) Classification des Fistules VésicoVaginales et Son Importance Pour les Données de Base. Fondation Genevoise Pour 
la Formation et la Recherche Médicales, Genève. http://www.gfmer.ch/Activites_internationales_Fr/PDF/Fistules_Hounnasso_2008

[2] Gutman, R.E., Lockwood, D.J. and Moswin, J. (2007) Complications of Treatment of Obstetric Fistula in the Developing World: Gynatresia, Urinary Incontinence, and Urinary Diversion. International Journal of Gynecology and Obstetrics, 99, S57-S64. https://doi.org/10.1016/j.ijgo.2007.06.027

[3] Joerg, H. (2011) Incontinence Urinaire de la Femme: Quelleest la Marcheàsuivre au Cabinet du Médecin de Famille? Forum Médical Suisse, 11, 830-835. https://doi.org/10.4414/fms.2011.07678

[4] Colas, J.M. and Blanchot, J. (2009) Incontinence Urinaire Après Réparation de Fistule Vésico-Vaginale. Mises à Jour en Gynécologie-Obstétrique et Techniques Chirurgicales. Collège National des Gynécologues et Obstétriciens Français, Paris, 583-589.

http://www.cngof.net/Journees-CNGOF/MAJ-GO/livres/2009_GO_483_colas.pdf

[5] Gueye, S.M., Diagne, B. and Mensah, A. (1999) Les Fistules Vésico-Vaginales: Aspects Etio-Pathogéniques et Thérapeutiques au Sénégal.

http://www.santetropicale.com/Resume/93902.pdf

[6] Benchekroun, A., Elalj, H.A., El Sayegh, H., Lachkar, A., Nouini, Y., Benslimani, L., et al. (2003) Les Fistules Vésico-Vaginales: A Propos de 1050. Annales d Urologie, 37, 194-198. https://doi.org/10.1016/S0003-4401(03)00053-6

[7] Kimassoum, R., Franklin, D.S., Arya, Z. and Kaboro, M. (2016) Evaluation du Traitement de l'Incontinence Urinaire Après Cure de Fistule Obstétricale. Uro' Andro, $1,142-146$ https://docplayer.fr/38344988-Evaluation-du-traitement-de-l-incontinence-urinaire -apres-cure-de-fistule-obstetricale.html

[8] Bernis, L. (2007) Obstetric Fistula: Guiding Principles for Clinical Management and Programme Development, a New WHO Guideline. International Journal of Gynecology \& Obstetrics, 99, S117-S121. https://doi.org/10.1016/j.ijgo.2007.06.032

[9] Delamou, A., Diallo, M. and Beavogui, A.H. (2015) Good Clinical Outcomes from a 7-Year Holistic Programme of Fistula Repair in Guinea. Tropical Medicine and International Health, 20, 813-819. https://doi.org/10.1111/tmi.12489

[10] Browning, A. (2006) Risk Factors for Developing Residual Urinary Incontinence after Obstetric Fistula Repair. BJOG, 113, 482-485. https://doi.org/10.1111/j.1471-0528.2006.00875.x

[11] Dumurgier, C.L. and Falandry, L. (2012) La Chirurgie des Fistulesobstétricales. Bulletin de P Académie Nationale de Médecine, 196, 1535-1556.

https://doi.org/10.1016/S0001-4079(19)31679-6

http://www.academie-medecine.fr/wp-content/uploads/2013/10/tap-pages-1535-15 56.pdf

[12] Munoz, O., Bowling, C.B., Kimberly, A.G., Taryor, R., Andy, M.N., Szychowski, J.M., et al. (2012) Facteurs Influant sur les Résultats Post-Opératoires à Court Terme de la Réparation de Fistulevésico-Vaginale dans un Hôpital Communautaire au Libéria. British Journal of Medical and Surgical Urology, 34, Article No. 91. https://doi.org/10.11604/pamj.2019.34.91.20547

[13] Waaldjik, K. (1989) The Surgical Management of Bladder Fistula in 775 Women in Northern Nigeria.

http://www.isofs.org/wp-content/uploads/2014/06/obstetric_fistula_PhD_thesis_19 89_full_report.pdf

[14] Demisew, A., Ahadu, W.A. and Desta, H. (2016) Caractéristiques et Réparation des 
Résultats des Patients Atteints de Fistule-Vésico-Vaginale Gérés à l'Université Jimma Enseignement Hôpital, Ethiopie. BMC Urology, 16, Article No. 41.

https://bmcurol.biomedcentral.com/articles/10.1186/s12894-016-0152-8 https://doi.org/10.1186/s12894-016-0152-8

[15] Barone, M.A,, Widmer, M., Arrowsmith, S., Ruminjo, J., Seuc, A., Landry, E., et al. (2015) Breakdown of Simple Female Genital Fistula Repair after 7 Day versus 14 Day Postoperative Bladder Catheterisation: A Randomised, Controlled, Open-Label, Non-Inferiority Trial. Lancet, 386, 56-62.

https://doi.org/10.1016/S0140-6736(14)62337-0 